\title{
Capabilities of the INL ZPPR to Support Active Interrogation Research with SNM
}

\section{CAARI}

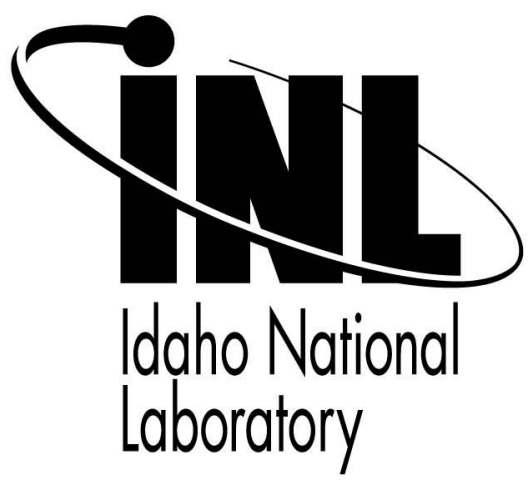

This is a preprint of a paper intended for publication in a journal or proceedings. Since changes may be made before publication, this preprint should not be cited or reproduced without permission of the author. This document was prepared as an account of work sponsored by an agency of the United States Government. Neither the United States Government nor any agency thereof, or any of their employees, makes any warranty, expressed or implied, or assumes any legal liability or responsibility for any third party's use, or the results of such use, of any information, apparatus, product or process disclosed in this report, or represents that its use by such third party would not infringe privately owned rights. The views expressed in this paper are not necessarily those of the United States Government or the sponsoring agency. 


\title{
Capabilities of the INL ZPPR to Support Active Interrogation Research with SNM
}

\author{
D. L. Chichester ${ }^{\text {a }}$, E. H. Seabury, J. A. Turnage, B. A. Brush, and E. F. Perry \\ Idaho National Laboratory, 2525 N. Fremont Avenue, Idaho Falls, Idaho 83415
}

\begin{abstract}
For over 40 years Idaho National Laboratory (INL) and its predecessor organizations have maintained and operated the Zero-Power Physics Reactor (ZPPR) as a test bed for studying reactor physics and nuclear reactor design. Although ZPPR is no longer operated as an active research reactor, its infrastructure (radiation shielding, safety systems, physical safeguards) and special nuclear material (SNM) inventory (variably enriched uranium and plutonium fuels available in metallic, oxide, alloy, and other forms) still make the facility a unique national resource for research and development activities involving the use of SNM. Recently INL has utilized this resource to serve as a test and evaluation facility for active interrogation research and development. This facility is currently hosting scoping experiments using neutron and x-ray radiation sources to characterize SNM active interrogation signatures and to develop tools and techniques to detect and identify shielded SNM. This paper presents an overview of the facility's infrastructure and assets and describes recent active interrogation experiments that have taken place using high-energy x-ray sources and compact electronic neutron generators.
\end{abstract}

Keywords: Active Interrogation, Special Nuclear Material, Electronic Neutron Generator

PACS: $29.20 . \mathrm{df}, 29.20 . \mathrm{Ej}, 29.25 . \mathrm{Dz}$

a) Idaho National Laboratory, MS-3740, P.O. Box 1625, Idaho Falls, ID 83415-3840, USA, Phone: (208) 526-8920, Fax: (208) 526-6239, Email: david.chichester@inl.gov 
INL/CON-08-14197

\section{Introduction}

The zero-power physics reactor (ZPPR, previously called the zero-power plutonium reactor) at Idaho National Laboratory (INL) was built in the late 1960's to provide researchers with a test-bed for evaluating reactor core design concepts and for benchmarking analytical reactor physics models and radiation transport simulation tools.[1,2] The reactor is a split-table-type critical facility comprised of two vertical walls opposing one another that contain small storage slots roughly $0.05 \mathrm{~m} \mathrm{x} 0.05 \mathrm{~m} \mathrm{x} 1.2 \mathrm{~m}$ ( 2 in $\times 2$ in $\times 48$ in) to hold material and fuel samples in a regular, square array of $4.27 \mathrm{~m} \mathrm{x} 4.27 \mathrm{~m}$. Today the reactor has been defueled and is no longer in use but its infrastructure and support facilities are still in operation and available. Most notably, research staff working at INL have the opportunity to access and use materials from the ZPPR fissile material storage vault. Access to special nuclear material (SNM) has become a challenge for research scientist in the United States and throughout the world over the past ten years as a result of activities trying to improve the physical safeguards and security of these materials. Notable examples include consolidations and material removal efforts at several U.S. national laboratories including Los Alamos National Laboratory, Lawrence Livermore National Laboratory, and Sandia National Laboratories. Of course, access to SNM in the academic and commercial sectors has always been difficult and current trends have further diminished capabilities in these areas as well.

At some time in the future excess SNM at ZPPR will also be removed for consolidation. However, since INL's core mission in the area of nuclear energy research and development requires access to plutonium and uranium to support advanced fuel cycle research and development, there is a level of burden sharing possible between the ZPPR-type storage activities and the storage activities needed for materials used in nuclear fuel development. Also, in order to support INL nuclear nonproliferation and safeguards research there is a programmatic mission need to retain access to reasonable quantities of these materials for non-fuel based work. Therefore, INL has decided to maintain SNM accessibility for research as a key capability into the future. Because of this accessibility INL is in a unique position to be able to support test and evaluation activities for INL staff working with bulk fissile material for instrumentation and system development. Since none of the materials in the INL ZPPR inventory are classified in shape or composition it is also possible for the Laboratory to host outside visitors that do not hold DOE security clearances, including individuals from universities and private industry, including foreign nationals. 


\section{INL/CON-08-14197}

This paper briefly describes salient features of the ZPPR facility and some of its unique material resources, followed by descriptions of some types of security-related research, development, and demonstration activities underway at INL and planned for the future. As a test and evaluation facility INL and ZPPR are ideally suited to support national laboratory, commercial, and academic investigators interested in exploring passive and active interrogation methods and instrumentation focusing on the problem of detecting, identifying, and characterizing fissionable material. The capability is complementary to larger-scale national nuclear material testing resources because of its flexibility and suitability for small-scale exploratory work, serving as an intermediate sand-box environment between prototype laboratory-scale development at individual institutions and full-scale, high-visibility advanced technology demonstration tests at the Nevada Test Site.[3]

\section{Facilities and Materials}

The ZPPR facility is located in INL's Materials and Fuels Complex (MFC), which was previously Argonne National Laboratory - West. It contains several test and evaluation work spaces within its security perimeter where SNM can be accessed including a workroom, the ZPPR reactor hall, and an outside area within the security perimeter. The workroom is square in layout measuring roughly $12.2 \mathrm{~m} \times 12.2 \mathrm{~m}(40 \mathrm{ft} \times 40 \mathrm{ft})$ in size. It has reinforced concrete walls and floors and a concrete ceiling with a thick earthen overpack. The room is well-suited for active interrogation measurements using x-rays or neutrons. The room also contains fissile material handling hoods where ZPRP fuel materials can be handled and arranged into storage containers, shipping containers, or specialized containers depending upon test objective requirements. The neutron background radiation level in the workroom is elevated above natural levels found in the area by about $5-10 \mathrm{X}$ due to the presence of SNM in storage at the site. One interesting attribute of this elevated background is that it may prove useful for instrumentation development and training exercises by imitating the elevated neutron background found at sea due to the "ship effect," providing a flexible laboratory environment to investigate "at sea" scenarios while ashore. $[4,5,6]$

The ZPPR reactor hall is a $15.2 \mathrm{~m}(50 \mathrm{ft})$ diameter circular room with reinforced concrete walls and floors and an earthen overpack ceiling. The reactor room is the most heavily shielded of the three test areas at ZPPR and ideally suited for high-radiation active interrogation testing using both neutron and x-rays. The outside test area at ZPPR is greater than $200 \mathrm{~m}^{2}$ and can accommodate large-sized objects including sea-land cargo containers. No 


\section{INL/CON-08-14197}

personnel are present to the East of the facility for several miles and test operations using high-energy bremsstrahlung interrogation sources could be used in this area when directed in that direction, or in other configurations when used in conjunction with a shield backstop.

Typical passive screening experiments at ZPPR involve the research team accompanied by support personnel including 2 fissile materials handlers, a facility work supervisor, a health physics technician, an INL subject matter expert - experiment coordinator (when supporting non-INL research), and protective force personnel. Research equipment can be driven up to the facility for unloading at the ZPPR security area entrance and stored for a short period of time before and after experiments; wireless communications equipment is not permitted in the facility. Active interrogation experiments are performed with a similar complement of personnel but additional health physics support is required for first-day testing with new radiation generation devices to determine and document radiation safety boundaries. Facility users must develop an experimental test plan and submit it for review and approval prior to being granted permission to conduct work in the facility.

Research activities using SNM at ZPPR are generally limited to a maximum of $18 \mathrm{~kg}$ of ${ }^{235} \mathrm{U}$ or $5.4 \mathrm{~kg}$ of

${ }^{239} \mathrm{Pu}$ and ${ }^{241} \mathrm{Pu}$. Mixed combinations of uranium and plutonium are also allowed. A partial listing of materials available for use at ZPPR is provided in Table 1. Depleted uranium, natural uranium, enriched uranium, plutonium, and uranium-plutonium mixtures are available in different matrix forms including pure metals, metal mixtures with $\mathrm{Al}$ and Mo, and oxides. For metal samples most items are available as thin plates on the order of $0.003 \mathrm{~m} \times 0.05 \mathrm{~m}$ $\mathrm{x} 0.05 \mathrm{~m}(1 / 8$ in $\mathrm{x} 2$ in $\mathrm{x} 2$ in) with some plates larger and smaller than this. Oxide samples are presented as rods with a diameter of $0.01 \mathrm{~m}$ ( $3 / 8 \mathrm{in})$ and lengths of $0.08 \mathrm{~m}$ to $0.16 \mathrm{~m}$ ( 3 in to 6 in).In all cases the materials are enclosed in thin-walled stainless steel claddings to prevent oxidation, damage, and contamination. Samples of uranium-233, neptunium-237, and thorium, as well as nonnuclear materials, are available also.

\section{Test and Evaluation Activities}

Recent passive screening work at ZPPR has included evaluation testing of personnel portal monitors, radiation survey instrumentation, and automated radiation identification instruments and algorithms. Also, as a part of this work the stand-off sensitivity and responsiveness of advanced SNM sensors has been evaluated under a variety of conditions. Within the ZPPR buildings, stand-off distances of greater than $20 \mathrm{~m}$ can be accommodated. Outside the building, much longer distances can be accommodated by placing materials inside the secure area and 
INL/CON-08-14197

positioning detection instrumentation beyond the perimeter security fence. Experimental set-ups may also be placed in the facility for long overnight periods to evaluate low signal intensity scenarios characteristic of the long-dwell intransit detection concept.

X-ray radiography measurements have been conducted inside the ZPPR workroom using $6 \mathrm{MeV}$ bremsstrahlung to evaluate instrumentation and techniques for analyzing bare and shielded uranium and plutonium metal assemblies. For this work the local dose rates near the accelerator x-ray source were greater than $0.01 \mathrm{~Gy}(1$ R) per min. To ensure personnel safety an operator control station was set-up on a table in an area adjacent to the workroom protected by heavy radiation shield doors (doors originally designed for personnel protection during ZPPR reactor operations). In addition to research activities the facility can also accommodate large groups of people and support instrumentation training and familiarization for passive and active interrogation. Active neutron interrogation measurements have also been conducted at ZPPR using electronic neutron generators (ENGs) producing 14.1 MeV neutrons. A photo of an experiment evaluating active neutron interrogation is shown in Figure 1. Although the radiation field generated by this device is much less than that from the $6 \mathrm{MeV}$ x-ray source, ENG control equipment a data acquisition system were again set-up in an area adjacent to the test location to maintain occupational exposures as low as possible.[7] A representative neutron die-away signature seen during interrogation measurements with a low-yield ENG using the set-up in the accompanying photograph is presented in Figure 2. These measurements were performed in the workroom area, which explains the elevated system background count rate in the $>2000$ microsecond region when no fissionable material is present.

\section{Summary}

Facilities capable of supporting passive screening and active interrogation with special nuclear material exist at Idaho National Laboratory's ZPPR which are now being used to support research and development and test and evaluation work. These facilities include different work areas including a potential "at sea" simulator (ZPPR workroom), a large and well shielded low-background room (ZPPR reactor hall), and an outside test area for largescale system testing and long stand-off detection investigations. Relevant quantities and types of special nuclear material are also available at ZPPR to support this work including samples with various uranium enrichments, samples with different grades of plutonium ranging from high quality ${ }^{239} \mathrm{Pu}$ test objects to reactor grade plutonium, and mixed uranium-plutonium samples, in both metal and oxide forms. Initial research at the facility has 
demonstrated the feasibility for conducting a variety of passive screening measurements and active measurement using both $6 \mathrm{MeV} x$ rays and electronic neutron generators. The facility regular hosts guests from throughout the U.S. and abroad and collaborative research and test and evaluation opportunities are possible with other national laboratories, academic institutions, and private industry.

1 Lawroski, H., et al., "Final Safety Analysis Report on the Zero Power Plutonium Reactor (ZPPR) Facility," Report ANL-7471, Argonne National Laboratory, Argonne, IL (1972).

2 Thalgott, F. W., et al., "ZPPR Enters a New Operating Era," Trans. Amer. Nucl. Soc. 27 (1977) 818-819.

3 "National Center for Combating Terrorism Strategic Plan," Report DOE/NV/11718-847, U.S. Department of Energy, Las Vegas, NV (2003).

4 "Environmental Measurements Laboratory Annual Report - FY2004," Report EML-625, Environmental Measurements Laboratory, New York, NY (2005) 9-11.

5 Katz, J. I., "Detection of Neutron Sources in Cargo Containers," Sci. Global Sec. 14 (2006) 145-149.

6 Gallagher, S. P. and Lanza, R. C., "Detection of Nuclear Weapons and Fissile Material Aboard Cargo Containerships," U.S. Patent 7,183,554 (2007).

7 Chichester, D. L. and Blackburn, B. W., "Radiation Fields in the Vicinity of Compact Accelerator Neutron Generators," IEEE Trans. Nucl. Sci. 55 (2008) 614-619. 
Table 1 Representative SNM material types available for test and evaluation work at ZPPR

\begin{tabular}{|c|c|c|c|c|c|c|c|c|c|c|c|c|c|}
\hline \multirow[b]{2}{*}{ Description } & \multirow[b]{2}{*}{ Form } & \multicolumn{4}{|c|}{$\begin{array}{l}\text { Composition } \\
(\mathrm{wt} \% \text { total } \mathrm{U})\end{array}$} & \multicolumn{5}{|c|}{$\begin{array}{l}\text { Composition } \\
(\mathrm{wt} \% \text { total } \mathrm{Pu})\end{array}$} & \multicolumn{3}{|c|}{$\begin{array}{c}\text { Composition } \\
(\mathrm{wt} \% \text { total } \mathrm{U}+\mathrm{Pu}+\mathrm{Am})\end{array}$} \\
\hline & & ${ }^{234} \mathrm{U}$ & ${ }^{235} \mathrm{U}$ & ${ }^{236} \mathrm{U}$ & ${ }^{238} \mathrm{U}$ & ${ }^{238} \mathrm{Pu}$ & ${ }^{239} \mathrm{Pu}$ & ${ }^{240} \mathrm{Pu}$ & ${ }^{241} \mathrm{Pu}$ & ${ }^{242} \mathrm{Pu}$ & $\mathrm{U}$ & $\mathrm{Pu}$ & ${ }^{241} \mathrm{Am}$ \\
\hline \multirow{2}{*}{$\begin{array}{l}\text { Depleted } \\
\text { Uranium }\end{array}$} & Metal & & 0.22 & & 99.78 & & & & & & 100 & & \\
\hline & Oxide & & 0.20 & & 99.80 & & & & & & 100 & & \\
\hline $\begin{array}{l}\text { Natural } \\
\text { Uranium }\end{array}$ & Metal & & 0.70 & & 99.30 & & & & & & 100 & & \\
\hline \multirow{4}{*}{$\begin{array}{l}\text { Enriched } \\
\text { Uranium }\end{array}$} & Metal & 0.91 & 93.24 & 0.44 & 5.41 & & & & & & 100 & & \\
\hline & Oxide & & 6.63 & & 93.37 & & & & & & 100 & & \\
\hline & Oxide & & 16.37 & & 83.63 & & & & & & 100 & & \\
\hline & Oxide & & 68.30 & & 31.70 & & & & & & 100 & & \\
\hline \multirow{3}{*}{ Plutonium } & \multirow{2}{*}{$\begin{array}{l}\text { Metal } \\
\text { w/ Al }\end{array}$} & & & & & 0.03 & 74.18 & 22.33 & 2.85 & 0.61 & & 98.23 & 1.77 \\
\hline & & & & & & & 95.20 & 4.52 & 0.20 & 0.07 & & 99.72 & 0.28 \\
\hline & $\begin{array}{l}\text { Metal } \\
\text { w/ Mo }\end{array}$ & & & & & & 95.29 & 4.54 & 0.18 & & & 99.79 & 0.21 \\
\hline \multirow{5}{*}{$\begin{array}{c}\text { Uranium } \\
\& \\
\text { Plutonium }\end{array}$} & \multirow{3}{*}{$\begin{array}{c}\text { Metal } \\
\text { w/ Mo }\end{array}$} & & 0.21 & & 99.79 & 0.09 & 68.73 & 26.38 & 3.38 & 1.43 & 64.64 & 34.61 & 0.75 \\
\hline & & & 0.22 & & 99.78 & 0.04 & 87.24 & 11.58 & 0.99 & 0.15 & 70.67 & 29.16 & 0.18 \\
\hline & & & 0.23 & & 99.77 & & 90.83 & 8.66 & 0.51 & & 79.94 & 19.98 & 0.08 \\
\hline & \multirow{2}{*}{ Oxide } & & 0.22 & & 99.78 & 0.07 & 69.98 & 26.12 & 3.69 & 0.14 & 82.02 & 17.80 & 0.19 \\
\hline & & & 0.22 & & 99.78 & 0.08 & 86.82 & 11.62 & 1.30 & 0.17 & 85.02 & 14.91 & 0.07 \\
\hline
\end{tabular}


Figure 1 An experiment at ZPPR using an electronic neutron generator and a moderated ${ }^{3} \mathrm{He}$ neutron detector to interrogate $2.2 \mathrm{~kg}$ of highly enriched uranium $\left(93.3 \%{ }^{235} \mathrm{U}\right)$

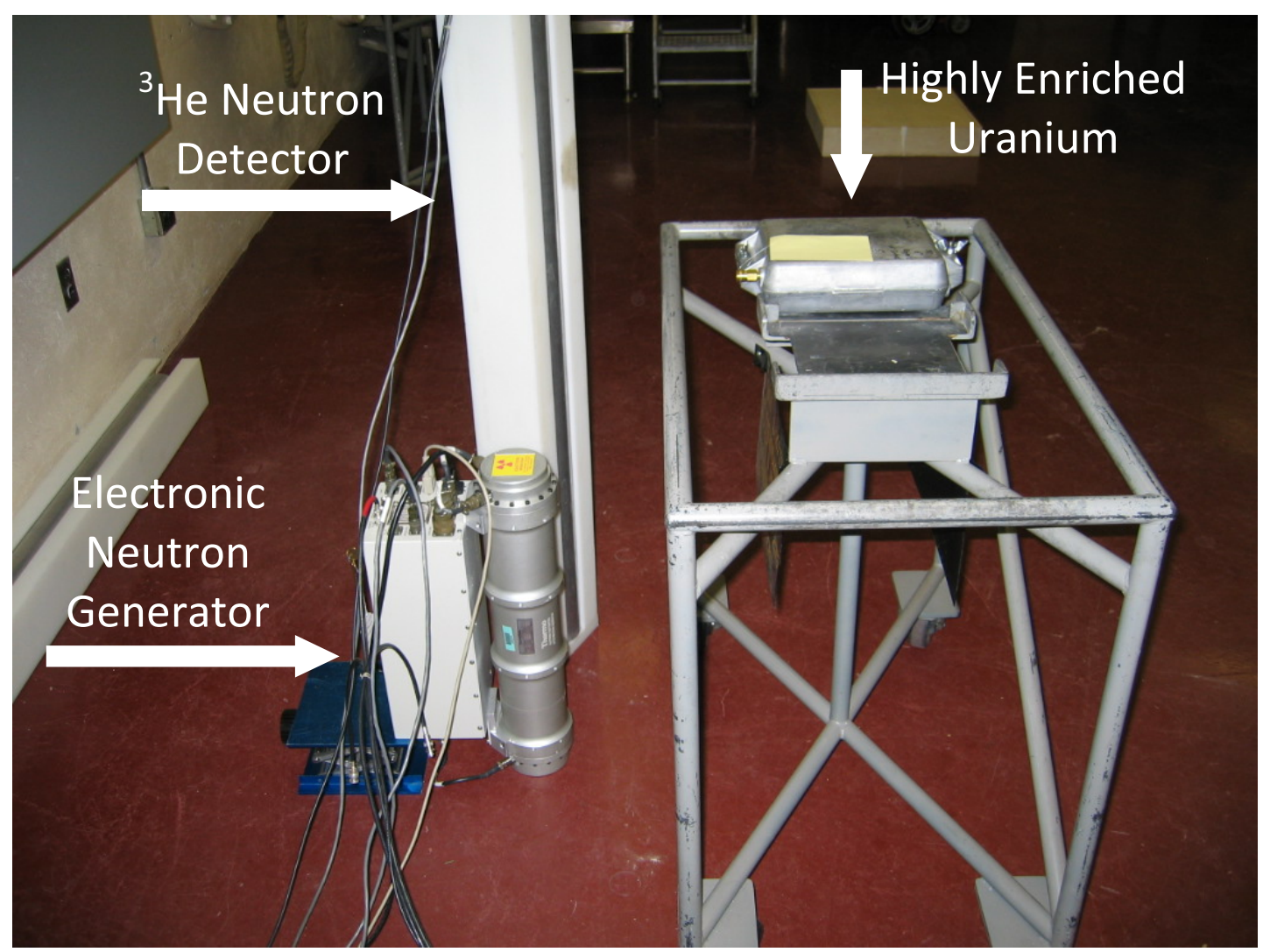


Figure 2 Representative active neutron interrogation signature using an electronic neutron generator ( $3.7 \mathrm{x}$ $10^{7}$ neutrons per second, $14.1 \mathrm{MeV}, 300 \mathrm{~Hz}$ pulse rate) to interrogate $2.2 \mathrm{~kg}$ of $\mathrm{HEU}$ for 500 seconds; calculation of the net signal difference was started at 700 microseconds, the neutron pulse ended at 333 microseconds

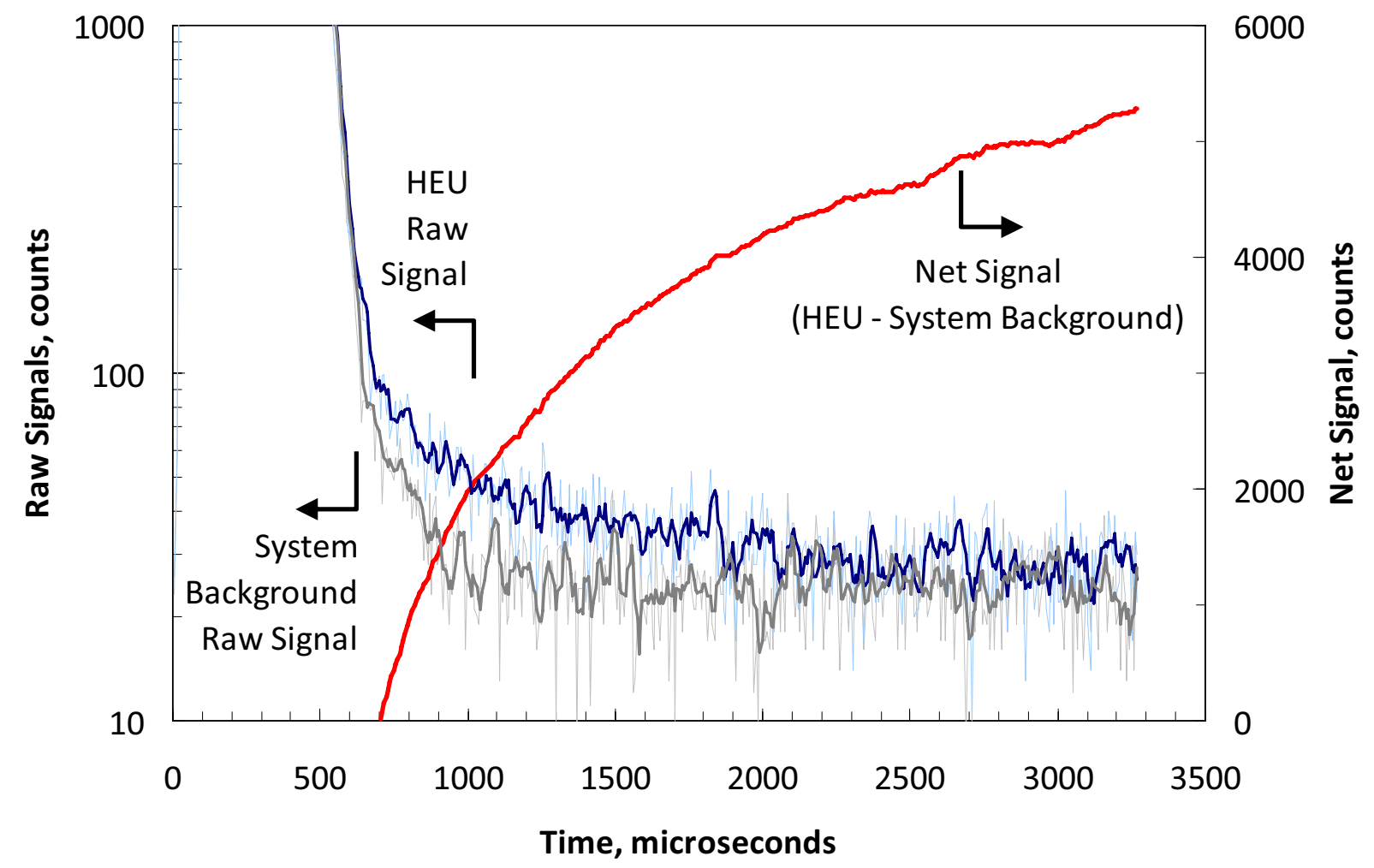

